\title{
Editorial Note on: The importance of verification and beta testing
}

Spinal Cord (2011) 49, 892; doi:10.1038/sc.2011.44; published online 10 May 2011

Editorial Note on: Spinal Cord (2011) 49, 886-891; doi:10.1038/sc.2011.23; published online 29 March 2011

Doctors use classifications of disease to allow clear, easy and accurate communication between health professionals in an area. For example, as colorectal surgeons, if a colleague asks us to review and treat a 42-year-old female ASA1, with a T2N1M0 rectal cancer at $12 \mathrm{~cm}$, we have a clear understanding of what he/she is talking about. Most importantly, these classification systems are used to compare management alternatives in similar patient groups and determine the best outcome for them.

Bowel dysfunction following spinal cord injury (SCI) is well described as a major cause of ongoing morbidity. ${ }^{1,2}$ The patterns of bowel dysfunction are well described, ${ }^{2,3}$ as are the causes, ${ }^{4,5}$ but the optimum bowel management regimens are still uncertain, thus leading to an important ongoing deficiency in management of patents after SCI.

The International SCI Bowel Function Data Sets, developed by a working group of experts appointed by American Spinal Injury Association (ASIA) and International Spinal Cord Society (ISCoS), were published in 2009. ${ }^{6,7}$ The International SCI Bowel Function Basic Data Set consists of 12 items and the International SCI Bowel Function Extended Data Set of 26 items. The combined data sets contain information for computation of the Cleveland Constipation Score, ${ }^{8}$ Wexner Fecal Incontinence Score ${ }^{9}$ and Neurogenic Bowel Dysfunction Score. ${ }^{10}$

The study by Juul et al. ${ }^{11}$ is important as it aimed to test the inter-rater reliability of the International Bowel Function Basic and Extended Data Sets as recommended by the Executive Committee for the International SCI Standards and Data Sets. Without this study, we could have little confidence in the relevance of the International SCI Bowel Function Basic and Extended Data Sets. The researchers are to be commended in undertaking the study in 'real time' in that those who scored the patients had no prior experience with the International SCI Bowel Function Data Sets and they did not undergo any specific training. Too often, in similar studies, enthusiasts for the proposed schemes are used, leading to a distortion of the results in favor of the project being studied.

As expected, there were a number of issues found with the data form. For example, it was not explicitly stated on the data collection form whether response categories were exclusive or not. In a number of cases raters selected several response categories when only one response was allowed.

It is important the ASIA and ISCoS allow beta testing of this form, and we would suggest they encourage and facilitate feedback to their groups (perhaps by a central email or face book), and then adjust the form as indicated. With such behavior, we might expect a clinically and research-useful document with a few further editions.

\section{A Stabler and FA Frizelle Christchurch Hospital and Burwood Spinal Unit, Christchurch, New Zealand E-mail: Frank.Frizelle@cdhb.govt.nz}

\section{References}

1 Glickman S, Kamm MA. Bowel dysfunction in spinal-cordinjury patients. Lancet 1996; 347: 1651-1653.

2 Lynch AC, Wong C, Anthony A, Dobbs BR, Frizelle FA. Bowel dysfunction following spinal cord injury: a description of bowel function in a spinal cord-injured population and comparison with age and gender matched controls. Spinal Cord 2000; 38: 717-723.

3 Lynch AC, Anthony A, Dobbs BR, Frizelle FA. Bowel function following spinal cord injury; a review. Spinal Cord 2001; 39: 193-303.

4 Lynch AC, Anthony A, Dobbs BR, Frizelle FA. Anorectal physiology following spinal cord injury. Spinal Cord 2000; 38: 573-580.

5 Lynch AC, Anthony A, Dobbs BR, Frizelle FA. Colonic neurotransmitters following spinal cord injury. Tech Coloproctol 2000; 4: 93-97.

6 Krogh K, Perkash I, Stiens SA, Biering-Sorensen F. International bowel function basic spinal cord injury data set. Spinal Cord 2009; 47: 230-234.

7 Krogh K, Perkash I, Stiens SA, Biering-Sorensen F. International bowel function extended spinal cord injury data set. Spinal Cord 2009; 47: 235-241.

8 Agachan F, Chen T, Pfeifer J, Reissman P, Wexner SD. A constipation scoring system to simplify evaluation and management of constipated patients. Dis Colon Rectum 1996; 39: 681-685.

9 Jorge JM, Wexner SD. Etiology and management of fecal incontinence. Dis Colon Rectum 1993; 36: 77-97.

10 Krogh K, Christensen P, Sabroe S, Laurberg S. Neurogenic bowel dysfunction score. Spinal Cord 2006; 44: 625-631.

11 Juul T, Bazzocchi G, Coggrave M, Johannesen IL, Hansen RBM, Thiyagarajan C et al. Reliability of the International Spinal Cord Injury Bowel Function Basic and Extended Data Sets. Spinal Cord 2011; 49: 886-891. 